\title{
En torno a los conceptos de protoauriñaciense, de auriñaciense arcaico, inicial y antiguo
}

(Unidad y variabilidad de los componentes tecnológicos de los primeros humanos modernos en el sur de Francia y norte de España

\author{
François Bon ${ }^{1}$, José Manuel Maillo Fernández ${ }^{2}$, David Ortega i Cobos ${ }^{3}$
}

\begin{abstract}
RESUMEN ABSTRACT
En esta breve introducción exponemos las motivaciones y desarrollo de la mesa redonda sobre el significado de las primeras fases del Auriñaciense a ambos lados de los Pirineos.

In this brief introduction, we expose the motivations and development of the workshop about the meaning of the early stages of Aurignacian on both sides of the Pyrenees.
\end{abstract}

\section{PALABRAS CLAVE KEYWORDS}

Auriñaciense, Francia, España. Aurignacian, France, Spain.

Durante las dos últimas décadas, el Auriñaciense ha sido objeto de una rica dinámica de investigación. Diversos coloquios y mesas redondas se han llevado a cabo en los últimos años, y se pueden encontrar por decenas los artículos sobre este tecnocomplejo (p. ej. Hays \& Thacker, 2001; Orschiedt \& Weninger, 2000; Blades, 2001; Goring-Morris \& Belfer-Cohen, 2003; Zilhão, Aubry \& Carvalho, 1999; Zilhão \& d'Errico, 2003). Sin duda, parte de este interés radica en que el Auriñaciense es la primera "cultura" correspondiente al Paleolítico Superior y, según la hipótesis más aceptada, ligada a la aparición de los Humanos Modernos en Europa. Dicho binomio (Humanos Modernos-Auriñaciense) tendría su origen en Próximo Oriente desde donde se desplazaría en poco tiempo hacia el occidente.

- UTAH-UMR 5608, Maison de la recherche, Université de Toulouse-Le Mirail, 5 allées A.-Machado 31058 Toulouse Francia. E-mail: bon@ univ-tlse2.fr.

2 Dpto. de Prehistoria y Arqueologia, UNED: jlmaillo@geo.uned.es.

3 Àrea de Prehistoria, Dpto. de Geografia, Història i Història de l'Art. Universitat de Girona: david.ortega@k.udg.es. 
Sin embargo, esta visión clásica y hasta hace algunos años apenas puesta en duda, se tambalea seriamente. La aparición de yacimientos o dataciones que escapan de esta dinámica, la ausencia de restos pertenecientes a humanos modernos hasta momento más recientes (Vandermeersch, 2003; Garralda \& Vandermeersch, 2004) hace plantearnos serias dudas sobre el modelo difusionista establecido. Por otro lado, debemos hacer referencia a que el Auriñaciense, en sus primeros momentos, no es un tecnocomplejo homogéneo (como cabría esperar en un modelo difusionista), sino que presenta numerosas variaciones tanto industriales como geográficas, lo que plantea incógnitas muy intensas sobre su origen, dispersión y naturaleza.

Con estos antecedentes son con los que decidimos realizar una reunión científica en la que poder discutir algunas de estas incógnitas. Sin embargo, partíamos del handicap de la extensión del Auriñaciense (casi toda Europa, e incluso aún más). Además, existen numerosos aspectos que deben ser tratados para entender, con detalle, tal tecnocomplejo. Por ello, y teniendo en cuenta que en trabajos de síntesis, en ocasiones se pierde capacidad de análisis profundo, decidimos acotar la temática del congreso en dos vías: por un lado circunscribimos el área de estudio a la región del norte de España y sur de Francia (del Golfo de León hasta la cornisa cantábrica) y, por otro, limitar a la industria lítica el tema de discusión.

La industria lítica representa, en la mayoría de los casos, el resto arqueológico más numeroso de los yacimientos arqueológicos. Probablemente, éste no sea el más importante para definir un tecnocomplejo o una cultura prehistórica, pero es la evidencia que tenemos y con ella debemos trabajar. Recientes aproximaciones desde la tecnología lítica intentan discernir elementos de carácter tradicional dentro de las diferentes facies del Auriñaciense, lo que, sin duda, parece una herramienta eficaz que debemos explotar (Bon, 2002, Maillo Fernández, 2003). Con este espiritu decidimos organizar el coloquio del que ahora presentamos sus actas. Justo sería reconocer que existen antecedentes a nuestra idea de realizar un coloquio de tecnología lítica del Auriñaciense en una región concreta. En el XIV Congrès de I'UISPP celebrado en Lieja en 2001 se celebró una mesa redonda titulada "Productions lamellaires attribuées à L'Aurignacien: Chaînes opératoires et perspectives techno-culturelles" coordinada por Foni Le Brun-Ricalens, desde donde se instó a la celebración de reuniones circunscritas a espacios geográficos más reducidos. Por supuesto, desearíamos que otros equipos de investigación tomaran nuestro testigo y realizaran encuentros similares al nuestro ( $p$. ej. el auriñaciense del este de Francia y del norte de Italia).

Dicha reunión se celebró en la Universidad de Toulouse -le Mirail entre los días 27 de febrero y 1 de marzo de 2003. En ella hubo lugar para la presentación de yacimientos, de resultados de Proyectos de investigación y de colecciones de algunos sitios arqueológicos, pero sobre todo, hubo lugar para largas discusiones en ambiente afable y distendido y, por supuesto, los autores son los únicos 
responsables de sus opiniones que son, en todo caso, expuestas de manera individual. Sin duda, debemos agradecer a numerosas personas e instituciones la posibilidad de realizar este encuentro, en particular las tres universidades inmersas en este proyecto: Universidad de Toulouse-Le Mirail, La Universitat de Girona y la Universidad Nacional de Educación a Distancia que colaboraron sin reservas desde diferentes estamentos para que pudiéramos organizar, ejecutar y publicar este coloquio. Deseamos también agradecer la ayuda financiera al Ministère de la Culture (Francia), el Conseil Régional de Midi-Pyrénées (Francia) y el Musée National d'Art et d'Histoire (Luxemburgo). Gracias también a todas las personas que las ayudaron a garantizar su buen desarrollo, en particular Sylvain Ducasse, Patricia Guillermin, Mathieu Langlais y Ritsu Motojima. Deseamos también recordar que este encuentro prolonga, hasta cierto punto, el realizado en el marco del PCR Comportements techniques et économiques des sociétés du Paléolithique supérieur en contexte pyrénéen, dirigido por Nathalie Cazals.

No queremos finalizar esta presentación sin recordar a una serie de profesores cuya influencia y resultados de sus investigaciones en los estudios sobre el Auriñaciense son esenciales en la actualidad. Henri Delporte y George Laplace que nos dejaron en los últimos meses y cuyos trabajos ha servido para articular las discusiones sobre este tecnocomplejo. Deseamos también asociar a este homenaje la figura de Denise de Sonneville-Bordes. Pero, ante todo, queremos recordar con especial cariño, la figura de Victoria Cabrera Valdés, desaparecida recientemente, la cual fue uno de los motores para que este coloquio se llevara a cabo y cuya aportación al conocimiento del Auriñaciense y su relación con el Paleolítico Medio, a través de los resultados de la cueva de El Castillo, han servido para revitalizar el debate sobre los primeros humanos modernos en el sudoeste de Europa.

A todos, gracias.

\section{BIBLIOGRAFIA}

BLADES, B. S. (2000): Aurignacian Lithic Technology. Ecological Perspectives from Southwestern France. Plenum Publishers, 208 págs.

Bon, F. (2002): L'Aurignacien entre Mer et Océan. Société Préhistorique Française, Mémoire XXIX, 253 págs.

Goring-Morris, A. N. \& Belfer-Cohen, A. (2003): More than meets the eye. Studies on Upper Palaeolithic Diversity in the Near East. Oxbow Books. 310 págs.

HAYS, M. A. \& THACKER, P. T. (2001): Questioning the Answers: Re-solving Fundamentals Problems of the Early Upper Paleolithic. British Arqueological Reports International Series, 1005, 202 págs.

Maillo Fernández, J. M. (2003): La transición Paleolítico Medio-Superior en Cantabria: análisis tecnológico de la industria lítica de Cueva Morín. Tesis Doctoral inédita. UNED, 547 págs.

Orschiedt, J.; Weninger, G.-C. (2000): Neanderthais and Modern Humans. Discussing the Transition. Neanderthal Museum, 322 págs.

ZiLhÃO, J.; Aubry, T. \& CaRVALho, A. F. (1999): Les premiers hommes modernes de la Péninsule Ibérique. Trabalhos de Arqueologia, 17, 170 págs.

ZILHĀO J; D'ERRICO F. dir. (2003): The chronology of the Aurignacian and the transitional technocomplexes: Dating, stratigraphies, cultural implications. Actes du symposium organisé dans le cadre du XIVème Congrès de l'UISPP, Liège, 2001. Trabalhos de arqueologia, 33, 355 págs. 